\title{
Experiences of Families Living with a Mentally Ill Family Member
}

\author{
Magdeline Monyaluoe, Mokoena-Mvandaba, Emmerentia du Plessis* and Magdalena P Koen
}

North-West University, Potchefstroom Campus, Private Bag X6001, Potchefstroom, South Africa

*Corresponding author: Emmerentia du Plessis, North-West University, Potchefstroom Campus, Private Bag X6001, Potchefstroom, South Africa, Tel: 018 299-1111/2222; E-mail: Emmerentia.DuPlessis@nwu.ac.za

Received date: January 27, 2014, Accepted date: June 9, 2014, published date: June 17, 2014

Copyright: (c) 2014 Magdeline Monyaluoe, et al. This is an open-access article distributed under the terms of the Creative Commons Attribution License, which permits unrestricted use, distribution, and reproduction in any medium, provided the original author and source are credited.

\begin{abstract}
Objective: To explore the experiences, describe the strengths to cope, and formulate recommendations to support families living with a mentally ill family member in the Thabo-Mofutsanyana district of the Free State Province in South Africa.
\end{abstract}

Method: A qualitative, phenomenological design, and in-depth interview guided by three central questions. A total of 14 interviews were conducted.

Results: Three main themes that were identified after data analysis: positive experiences and strengths, negative experiences, and support of families living with a mentally ill family member.

Conclusion: In order to address some concerns indicated by these families, and to strengthen their strategies in coping as individuals and as families, support recommendations were formulated. Further studies are needed to implement these recommendations and to evaluate their effectiveness.

Keywords: Experience; Family; Strengths; Mentally ill family member; Support system

\section{Introduction}

In South Africa, Mavundla, Toth and Mphelane state that after democratisation in 1994, in line with other countries, the health care system was re-organized in accordance with the primary health care philosophy [1]. The new Mental Health Care Act 17 of 2002 reflects the changes in mental health legislation [2]. Van Rensburg states that the emphasis has shifted to appropriate community-based care, rehabilitation and reintegration into the community [3]. This is supported by Uys and Middleton who indicate that the South African government accepted the policy of a comprehensive primary health care approach [4]. Although this was not initially implemented with enthusiasm, the African National Congress indicates that the new government is committed to this approach, as stated in the National Health Plan for South Africa [5]. In further support of primary health care, the purpose of the Mental Health Care Act is to ensure provision of care treatment and rehabilitation to people with mental illness [2]. In the Free State Province, where the Thabo-Mofutsanyana district is situated, and in line with other provinces, the province also provides primary health care services. This is supported by having the Provincial Mental Health Policy 2004 with its vision in pursuit having a healthy and self-reliant Free State Province community [6].

Similar to international trends $[7,8]$ mentally ill patients have been systematically deinstitutionalised in South Africa during the last two decades [4]. This is confirmed by Mavundla, Toth and Mphelane who state that due to overcrowding in mental hospitals, a process of deinstitutionalization of mental health care services started which led to families becoming the main providers of individuals with mental illness [1]. To further support this, Du Plessis, Greeff and Koen indicate that deinstitutionalisation of mentally ill patients was implemented by the government of the North West Province in South Africa, where as many as possible psychiatric patients were discharged from long term hospitals to be under care of their families [9].

However, the shift to a primary health care approach heightens the importance of understanding the effect of this approach on the families living with a mentally ill family member [10]. In research done on this topic in Ireland; findings confirm that family carers play an important role in the care, treatment and rehabilitation of mentally ill family members [11]. Moreover, in America, the United States Department of Veterans Affairs (AV) health care system is working to develop family and caregiver support programmes to enable veterans with mental health problems to remain at home with community-based support service [12].

In addition, Japan is in support of a comprehensive care system that involves support and provision of care at home, arguing that to effectively deal with challenges associated with prolonged hospitalization of mentally ill patients, it is essential to switch to community psychiatric care system [13]. Furthermore, family support is seen as very important to the successful rehabilitation and recovery of a person with mental illness[7]. Apart from the pure emotional support that is given by carers, there are many other practical examples of support, such as cooking, household chores, assisting with keeping medical appointments and financial support [14].

But, contrary to the support the family is supposed to give, families might experienced that they are forced to fulfil the role of caregiver to their mentally ill family member, as was the case in Malaysia where not many of the families were ready to accept, or were properly prepared to undertake this role [8]. Even though families are expected to provide care to their mentally ill family members, it seems that they 
are faced with many challenges, such as a lack of understanding and skills related to mental illness [15].

Similarly, providing continued care and support for people with mental illness is demanding and challenging [16]. Families often become frustrated, stranded, overburdened and exhausted by the care of their relatives [10]. Families may experience a substantial burden on their emotional and social integrity, combined with diminished psychological well-being, as was seen in a study in New South Wales, Australia [17]. Furthermore, caring for a person with mental illness can be overwhelming, challenging and a distressing experience [18]. Ahlström, Skärsäter, and Danielson found that family members are forced to relinquish control of everyday life; family members lose their energy and cannot manage everyday life, families are unstable and emotions influence the atmosphere negatively, and they periodically live in seclusion [19].

In addition, Stjernswärd and Ostman discuss how families express a feeling of not living their own life, struggling to balance relationships, adapting to and re-evaluating their life circumstances, and struggling to voice their ill relatives' and their own needs[20]. Furthermore, this also has a negative impact on the family member who has chosen not to help the care giving; family members who decide to put their own needs ahead of the needs of their mentally ill family member end up feeling guilty, ashamed, or depressed [21]. Stuart adds that families, including mentally ill family members do not receive adequate pertinent information about mental illness or effective support from mental health professionals [7]. As a consequence, families feel that their attempt to care is not supported by the health care system [18]. In addition, carers frequently feel marginalized and undervalued, and believe that the impact of mental illness on them as carers has not been recognized, and they might feel "invisible" to medical services [14].

It is thus clear that families living with a mentally ill family member might find it difficult to cope. In my own experience, while accompanying learners for mental health care services for experiential learning, I informally observed how families interact with mentally ill family members. It seemed that families have no knowledge on how to handle a mentally ill family member. In addition, mental health care services (clinics) designated to provide mental health care, and where mentally ill family members attend follow up appointments, seemed not to have a formal support system for these families. It was unclear how these families cope. The researcher could confirm this statement after spending some time in the research field as part of the preparation for this research.

Therefore, the focus of this research was to develop recommendations to address the gap in supporting the families living with mentally ill family members. Moreover, in South Africa, in the Free State Province and specifically in the Thabo-Mofutsanyana district, limited research has been conducted on the strengths of families to cope with mentally ill family members. This seems to be important, as research has reported that in spite of adversities, some families make conscious efforts to cope [22] and survive by using their strengths such as living with hope, remembering good times, enduring and accepting reality, and seeking professional help [18]. Haung, Sun, Yen, and Fun also state how families with mentally ill members used strengths such as positive thinking and knowledge, behavioral coping strategies and crying as emotional release [23]. It is thus suggested that future studies need to focus on strengths to devise feasible interventions or strategies to lessen economic, social psychological and emotional burdens for family members and carers [24].
The above argumentation resulted in the following research problem: The experiences of families Thabo-Mofutsanyana district living with a mentally ill family member should be explored and described in order to gain insight into difficulties they encounter as well as identify strengths they have in coping while living with a mentally ill family member The following questions were formulated to target this problem:

\section{Research Questions}

What are the experiences of families living with a mentally family member in the Thabo-Mofutsanyana district?

What strengths do families living with a mentally ill family member have in coping?

How can families living with mentally ill family members be supported?

These research questions led to the following objectives:

To explore and describe the experiences of families living with a mentally ill family member.

To explore and describe the strengths of families to cope with living with a mentally ill family member.

To formulate recommendations to support families living with mentally ill family members.

\section{Method}

A discussion of the research method follows below.

\section{Paradigmatic perspective}

In the initial phase of the research, a paradigmatic perspective was determined, which implies the way in which the researcher views the research material [25]. The paradigmatic perspective for this research was based on assumptions applicable to the research domain and Husserl's philosophy that a phenomenon occurs only when there is a person who experiences the phenomenon and that the experience must be described $[26,27]$. This project contains the characteristics of a scientific process because a scientific and systematic approach was used [28].

\section{Sampling method}

The population studied in this research consisted of families living with a mentally ill family member in the Thabo-Mofutsanyana district in the Free State Province in South Africa. Purposive sampling was used to select participants who complied with inclusion criteria, and who voluntarily agreed to participate. The inclusion criteria included that participants should have been family members living with a mentally ill family member in their home; over the age of eighteen; and be able to communicate in Sesotho or English.

Sampling was carried out with the assistance of a mediator who is working for a clinic in the Free State Department of (FSDoH) that is dealing with mental health care users in the Thabo-Mofutsanyana district, and who are well known to the families living with mentally ill family members. In this way, the selected sample was more representative of the population because the mediator forms part of the current support system for families living with a mentally ill family member. 


\section{Sample size}

Sample size was determined by data saturation [27], namely that the process of purposive sampling continued until a sufficient amount of data was obtained to draw valid conclusions, and until no new themes came forth. 14 interviews were conducted, after which the experiences of living with a mentally ill family member were clear and a pattern in the data had become evident. Two to three family members participated in each interview, representing a total of 14 families. These family members were parents, spouses or siblings of the mentally ill family members, and were all adults (between 18 years and 50 years of age). The relevant mentally ill family members were mainly diagnosed with mood disorders, substance abuse or schizophrenia, and were living with and dependent on their family members.

\section{Data collection}

Congruent with the qualitative, phenomenological research design that was chosen for this research, data was collected by in-depth interviews with families living with mentally ill family members. The interviews were conducted from June 2011 until August 2011, with the purpose of exploring experiences of families living with a mentally ill family member as well as their strengths to cope with living with a mentally ill family member. A tape recorder was used to record the interviews which all lasted for approximately 45 minutes to an hour. The interviews were predominantly guided by two open-ended questions, namely:

What are your experiences living with a mentally ill family member?

What strengths do you have to cope while living with a mentally ill family member?
How can you as a family living with a mentally ill family member be supported?

Additionally, the researcher used interpersonal skills for probing and clarifying [27].

Experts in qualitative research were consulted to evaluate these questions and a trial run within the field was undertaken. The interviews took place in a comfortable room at one of the clinics which provides mental health care services. There was no set time-limit for the interviews, because the length of the interviews strongly depended on the specific interview situation. After the interviews, field notes which were used to supplement and verify the voice recording were written down as soon as possible [25].

\section{Data analysis}

After having recorded the interviews on a tape recorder, they were transcribed verbatim. The data analysis commenced after the first interview and was carried out simultaneously with the data collection. The transcripts were translated from Southern Sotho to English with the help of translators from the North-West University. The initial data analysis guided decisions concerning further data collection [27]. Open coding was used for analyzing the transcribed data and a cocoder, an experienced qualitative researcher, coded the data independently [26,27]. A work protocol was developed by the researcher and provided to the co-coder according to which data was analysed. During telephonic consensus discussions, the researcher and the co-coder discussed the coding themes and consensus was reached on the main and subcategories in order to ensure the trustworthiness of the data analysis (Table 1) $[27,29,30]$. The field notes were used to enrich and confirm the findings.

\begin{tabular}{|l|l|l|}
\hline $\begin{array}{l}\text { Positive experiences and strengths of families } \\
\text { living with a mentally ill family member }\end{array}$ & $\begin{array}{l}\text { Negative experiences of families living with a mentally ill } \\
\text { family member }\end{array}$ & $\begin{array}{l}\text { Support of families living with a mentally ill family } \\
\text { member }\end{array}$ \\
\hline $\begin{array}{l}\text { Accepting living with mentally ill family member } \\
\text { Assistance by community members }\end{array}$ & $\begin{array}{l}\text { Families find it difficult and painful to live with a mentally ill } \\
\text { family member } \\
\text { Family members blame themselves for having a mentally ill } \\
\text { Families desire the best treatment for their mentally } \\
\text { family member }\end{array}$ & $\begin{array}{l}\text { Families need informal and formal support while } \\
\text { living with a mentally ill family member }\end{array}$ \\
$\begin{array}{l}\text { Families obtain formal support for mentally ill family } \\
\text { Families experience themselves as at risk of being injured } \\
\text { or killed by their violent and aggressive mentally ill family } \\
\text { member }\end{array}$ & $\begin{array}{l}\text { Families experience health problems as a result of living } \\
\text { with mentally ill family members } \\
\text { Families are concerned about mentally ill family members' } \\
\text { behavior }\end{array}$ \\
\hline
\end{tabular}

Table1: Experiences and strengths of families living with a mentally ill family member.

\section{Trustworthiness}

To ensure further trustworthiness of this research, the researcher applied Klopper's principles for assessing the trustworthiness of qualitative data [30]. The article describes four epistemological standards of trustworthiness; truth value, applicability, consistency and neutrality, which were applied to this research. These standards were ensured by means of techniques such as prolonged engagement with participants, triangulation by involving an independent co-coder during data analysis, peer examination, dissemination of report results, dense descriptions, external reviewand the use of field notes.

\section{Ethical Considerations}

This research formed part of the RISE project (Strengthening the resilience of health caregivers and risk groups), with ethical clearance from the Ethics Committee of the Faculty of the North-West University, Potchefstroom Campus and Head of the Department of Health in the Free State Province. This research could have been threatening to human rights due to the high stigmatization of families living with mentally ill family members in South Africa. Since this also applies to the Thabo-Mofutsanayana district, a primary concern in this research was confidentiality. Privacy for the participants was ensured 
at both types of venue and identity of the participants was kept confidential at all times. Because all participants had the right to know what participating in this research entailed and to voluntarily participate, informed consent was ensured before all interviews [28]. The participants were protected from physical and psychological discomfort and a qualified psychologist was available for referral to support the participants after interviews when needed [28].

The researcher adhered to the ethical aspects linked to this research and the project was carried out with integrity and in a scientifically honest fashion.

\section{Results}

Three categories emerged from the data analysis: Positive experiences of families living with a mentally ill family member, negative experiences of living with a mentally ill family member and support of families living with a mentally ill family member (Table 1).

\section{Positive Experiences of Families Living with a Mentally Ill Family Member}

\section{Accepting living with mentally ill family member}

Participants stressed that they have learned to accept and live with their mentally ill family members even though they often feel that they are in-competent to play their role as a supportive family. For example, one family member shared the following: "I had to understand the situation and accepted to live with the condition, stayed in that condition in order to know this person". Sales et al. [31] also found that family members were willing to learn to live with the mentally ill person. Leeet al. [32] even found that family members felt that they had no choice but to accept the mentally ill family member.

\section{Assistance by community members}

Participants shared that they were supported by community members to look after the mentally ill when the family members are not around, reprimanding the mentally ill when misbehaving, or taking him to the clinic for treatment. They added that they even experience more support from community members than from their own relatives. One participant said: "But I have even requested one of my neighbors to check on her. There is a certain lady who is very young, who is of my daughter-in-law's age, she is staying at home, I have requested her to check on her on what might happen". Sales et al. [31] also pointed out the experiences of support from community members and prejudice and conflict with relatives with regards to mentally ill family members.

\section{Education by nurses}

Participants experienced supporting their mentally ill family member in obtaining treatment as very important. Education was reported to be one of the most important needs for these families. The families reported how they want nurses to teach them things like: signs and symptoms of relapse, how to handle a mentally ill person when he or she has relapsed and is aggressive, and how and when to seek assistance. One participant said: "They must come and teach us how to handle him when he has relapsed, and when he is aggressive, and how and when to seek assistance. He sometimes refuses to take treatment," $\mathrm{Du}$ Plessis et al. [9] support that the family needs support from healthcare professionals, such as mental health education.

\section{Families desire the best treatment for their mentally ill family member}

Furthermore, participants reported that they want the best treatment for their mentally ill family members. In addition, family members reported that mentally ill family members improve when they are given treatment. However, some families reported that their mentally ill family members abuse substances such as cannabis, which worsens their condition. This strains the relationship between family members and the mental health care user. One participant related her situation as follows: "He smokes dagga and he has been continuously using dagga (cannabis) and that is one thing that I need to be assisted with." The Mental Health Care Act [2] also emphasizes that menta health care users should receive the best treatment possible, irrespective of their condition and/or behavior.

\section{Families obtain formal support for themselves and their mentally ill family member}

The participants reported that because they wanted the mentally ill family members to obtain help, they obtain formal support in the form of traditional healers and prophets, churches and health care services such as clinics and hospitals. The following quotation supports these results: "The clinic has also helped a lot because she is collecting her treatment on monthly basis, and it has helped a lot because it made the condition to subside and she is no longer roaming around the streets."Du Plessis et al. [9] also found that families make use of formal support available.

\section{Negative experiences of families living with a mentally ill family member}

Families find it difficult and painful to live with a mentally ill family member. It seemed from the results that the families were experiencing some difficulties, and they were also experiencing much pain. Some participants had some difficulties because people around their area discriminated against them, while other participants reported that it was difficult because he is self-employed, and had to provide for the family. Participants stated: "It is very difficult because people around our area know that he is mentally ill." "It is very difficult because I'm not working and I'm self-employed, but whatever I put on the table I share with him". Some families expressed their emotions, where they reported how painful it was when looking at their circumstances. It was painful because the mentally ill family members would do things that were unacceptable, for example, undressing in public, and behaving like children. Despite these circumstances, they continue to live with the mentally ill family member, and said: "It was painful in the sense that my daughter was not like this, particularly when she does unusual things, Uh! Things like unable to stay still I mean she keeps on doing funny things that do not make us happy". Stjersward and Ostman [20] confirm these by stating how families expressed a feeling of pain not living their own life, struggling to balance relationships, adapting to and re-evaluating their life circumstances, and struggling to voice their ill relatives' and their own needs.

\section{Family members blame themselves for having a mentally ill family member}

In addition, some family members blamed themselves for having mentally ill family members. Furthermore, participants explained how they would feel embarrassed and ashamed, and this feeling of 
embarrassment was fuelled by the actions performed by their mentally ill family member. The following were expressed by a family member: "I had to learn a lot during the time when I was still angry with her, and I even asked God to say: What have we done?" Families might view mental illness as linked with spirituality.In this study, some families revealed that they still believe in superstition and witchcraft. The results revealed how some family members believed that their mentally ill family members suffered from mental illness because of witchcraft, while others believed that they suffered due to spirituality. A participant shared the following:

"I asked the family members about the condition by saying what kind of illness is this? They were not sure because, they were saying it is like she is having stress or witchcraft. It seems as if she is the person with spirituality". Chanet al. [15] confirms that families are expected to provide care to their mentally ill family members, even though they were faced with many challenges such as lack of understanding about mental illness.

\section{Families experience themselves as at risk of being injured or killed by their violent and aggressive mentally ill family member}

During the interviews, it became clear that families felt at risk of being injured or killed by their violent and aggressive mentally ill family members, and as such, families live in fear. Some family members reported that they were attacked by their mentally ill family members. Destruction to property was reported as experienced by many families, moreover the results revealed that it is one of the risks of injuries. A participant shared: "She is destroying things, she is destructive, and she destroys anything she touches." Mavundla et al. [1] had similar findings, namely that physical aggression and destructive behavior from the mentally ill is an aspect that puts their own physical and mental well-being at risk and is seen as a barrier to provision of their support.

\section{Families experience health problems as a result of living with mentally ill family members}

In this study, some families were affected by the negative experiences of living with a mentally ill family member resulting in some health problems. The results indicate the health problems which were common amongst the family members. The participants reported that they suffered different health problems, in so much as that some of them are even receiving treatment. The health problems mentioned include confusion, stress, depression, and hypertension. For example, a participant shared: "I would complain to my mom and become inpatient with her, and request my mom that I cannot tolerate my sister, and I would be stressed up". Similar findings were reported by Mavundla et al. [1] that the fact that families adjust their social lives to the needs of their relatives with mental illness is a source of stress, as they no longer have time for themselves. Trondsen [33] also found in her study that mental illness led to strained relationship and ambivalent feelings.

\section{Families are concerned about mentally ill family members' behaviour}

The results revealed how families were concerned with some of the behaviours of their mentally ill family members. The concerns which the families reported are: aggression, violence, verbal abuse, substance abuse, heavy smoking, damage to property, disrupting other people, and poor personal hygiene. One participant related the situation as follows: "When I sometimes talk to him, he does not want to listen to me. He becomes aggressive. Sometimes he becomes a changed person all together, and becomes very angry". Trondsen [33] as well as Lauber and Rossler [34] confirm that families are concerned about and sometimes even fear mentally ill family members' unpredictable and socially unacceptable behavior.

\section{Support to families living with a mentally family member}

Families need informal and formal support while living with a mentally ill family member. During interviews, the third question asked was: "How do you want to be supported as a family?" All participants felt that they wanted to be supported both informally and formally while they lived with mentally ill family members in their homes. The participants reported that the support they need will consistently give them courage in the care for their mentally ill family members. Family members need support from the Department of Health, clinics, rehabilitation centers, the community and/or neighbors, other mental health care users and support groups. For example, participants shared the following:"If it is possible, his life should better be rehabilitated more than it is right now". "I don't know because, we want the very patient to be rehabilitated". Another participant shared: "I expect that there should be nurses who should visit her, and check on her on a daily basis whether she gets her treatment. Sometimes they should come and visit the families to go and check whether she gets her treatment properly". Trondsen [33] Sales et al. [31] as well as Jivanjee and Kruzich [35] confirm that families need support from health care professionals and from friends and community members.

\section{Recommendations proposed to support families living with a mentally ill family member}

In congruence with the objectives of this research, recommendations for effective support for families living with a mentally ill family member in the Thabo-Mofutsanyana district in the Free State Province are proposed. The purpose of these recommendations is to improve and strengthen the support given to the families living with mentally ill family members in this area. The recommendations are meant to be implemented by mental health care practitioners, particularly nurses working at the clinics in this area. They must be used in conjunction with existing policies and protocols, and within the legal framework of the Mental Health Care Act 17 of 2002 , in order to support the families living with mentally ill family members more effectively [2]. The recommendations are as follows:

Mental health care practitioners should acknowledge and utilise the strengths of families caring form a mentally ill family member by reflecting with these families on their strengths and how they can use their strengths to cope with negative experiences and their need for support.

Mental health care practitioners should address the challenges of family members who feel incompetent and strengthen the families that are competent in giving basic care to their mentally ill family members by teaching them basic skills. This can be done by giving them health education at the clinic according to the needs of the families. This includes skills such as: how to handle an aggressive patient, whom to call, where to refer the mentally ill to, as well as the rights of mental health care users. 
An education program can be implemented at the clinic for families living with mentally ill family members. This education program should be structured in such a way that both the families and the mentally ill family member are accommodated. This can be done by conducting workshops, seminars, in-service training related to mental health issues for families living with a mentally ill family member, for example, causes of mental illness, treatment, personal hygiene and so forth.

Stigmatization and discrimination of families living with mentally ill family members, including the mentally ill, can be reduced by holding awareness campaigns periodically. This can be done by mental health care practitioners in conjunction with the families and interested stakeholders who are assisting with mental health activities, for example, non-governmental organizations as a way to support these families.

Mental health practitioners can play a major role in advocating for mental health care users for rehabilitation. Rehabilitation should be comprehensive in the sense that it should look at psychological, social, and physical being of the mental health user. The process of rehabilitation of mental health care users who abuse dagga can be facilitated by the mental health care practitioner through communication and engagement with other health care professionals, for example, social workers.

Home visits can be done by drawing up the clinic programme in such a way that mental health practitioners visit families of mentally ill family members in their homes. While they visit families in their homes, this will allow them to assess the home situation, give information on certain topics, and also supervise them in giving medication.

Cultural support and spiritual support can be facilitated by integrating traditional healing and spirituality in the current health care system of families living with mentally ill family members. In addition, mental health care practitioners should encourage religious organizations and churches to be open about mental illness and offer support to the families and refer the mentally ill to the relevant community mental health resources, for example, clinics, hospitals, and community centers. Mental health care practitioners can support and assist families living with mentally ill family members to establish a support group. This could be met by identifying and recruiting all families living with mentally ill family members in this area, and who are interested in joining the support group. The support group can start with a small number of family members, and the steps or principles of establishing a support group can be followed. As the group develops, it can be left to the families to take ownership. Furthermore, families living with mentally ill family members should be encouraged to support and encourage other families to disseminate correct information about mental illness within the community.

\section{Limitation of the Study}

As a qualitative study, the research findings were contextual and cannot be generalized. However, an audit trail is provided so that the study can be duplicated in other contexts if the need exists. The authors also acknowledge that data gathering methods additional to the interview data could have enriched the data and research findings.

\section{Conclusion}

In conclusion, it can be stated that the objective of exploring the experiences and the strengths of families living with a mentally ill family member in the Thabo-Mofutsanyana district was met and led to the formulation of recommendations to support these families. The recommendations can serve as a useful tool for mental health care practitioners who are working with families that are living with a mentally ill family member. These recommendations can be used to guide and empower professional nurses, family members, community members, relatives, and other health care practitioners in assisting families living with mentally ill family members.

\section{Ethical Issues and Conflict of Interest}

The authors declare that relevant ethical principles were adhered to, and that there is no conflict of interest that they are aware of.

\section{Acknowledgements}

The authors would like acknowledge Dr Vicki Koen for her assistance in the final preparation of the article. We would also like to acknowledge Johnson and Johnson South Africa for financial assistance during the study.

\section{References}

1. Mavundla TR, Toth F, Mphelane ML (2009) Caregiver experience in mental health: A perspective from a rural community in South Africa. Int J Ment Health Nurs; 18: 357-367.

2. South Africa. Mental Health Care Act 17 of 2002. Cape Town: Government Printer 1-78.

3. Van Rensburg BJ (2005) Community placement and integration of service users from long-term mental health care facilities. S Afr Psychiatry Rev 8:100-103.

4. Uys L, Middleton L. Mental health nursing. A South African perspective, 5thedn. Cape TownJuta 2010.

5. ANC. African National Congress (1994) A National Health Plan for South Africa. Johannesburg Taj 21-22.

6. Provincial Mental Health Policy (2010) Health and substance abuse office. Policy No 8/5.1./3 P1. Free State Province 1-17.

7. Stuart GW. Principles and practice of psychiatric nursing. 9thedn. Missouri: Mosby.

8. Chang KM, Horrocks S (2006) Lived experiences of family care givers of mentally ill relatives. J AdvNurs53:435-44.

9. Du Plessis, E, Greeff, M, Koen, MP (2004) the psychiatric outpatient's family as a support system. Health SA Gesondheid 9: 3-19.

10. SeloilweS (2009) Experiences and demands of families with mentally ill people at home in. JNursScholarsh38: 262-268.

11. O'Doherty YK, Doherty DT (2008)Coping strategies and styles of family carers of persons with enduring illness: a mixed methods analysis. Scand J Caring Sci22: 19-28.

12. Sorrel JM,Durheim S (2011) Meeting the mental health needs of the aging veteran population: A challenge for the 21st century. J Psychosocial Nurs and Mental Health Services49: 24.

13. Fujino N, Okamura H (2009) Factors affecting the sense of burden felt by family members caring for patients with mental illness. ArchPsychiatrNursing23: 128-137.

14. Jones K (2009) Addressing the needs of carers during early diagnosis. Early intervention in Psychiatry3: 522-526.

15. Chan S, Yip B, Tso S, Cheng B, Tam W (2009) Evaluation of a psychoeducation program for Chinese clients with schizophrenia and their family caregivers. Patient EducCouns75: 67-76. 
Citation: Monyaluoe M, Mvandaba M, Plessis ED and Koen MP (2014) Experiences of Families Living with a Mentally III Family Member. J

Page 7 of 7

16. Hsiao C (2010) Family demands, social support and caregiver burden in Taiwanese family caregiver living with mental illness: the role of family caregiver gender. J ClinNurs19: 3494-3503.

17. Wilson R (2011) Experiences of families who help young rural men with emergent mental health problems in a rural community in New South Wales, Australia (In World Congress of the world Federation for Mental Health. Abstract poster presentation at World Congress of the Federation for Mental Health held in Cape Town on 17 to 21 October 2011. Cape Town. p. 135-136.)

18. Endrawes G, O’Brien L, Wilkes L (2007) Egyptian families caring a relative with mental illness: A hermeneutic study. Int J Ment Health Nurs; 16: 431-440.

19. Ahlstrom Skarsater, Ahlstrom BH, Skarsater I, Danielson E (2009) Living with major depression: experiences from families' perspective.Scand J Caring Sci23: 1- 21

20. Stjernsward S, Ostman M (2008) whose life am I living? Relatives living in the shadow of depression.Int J Soc Psychiatry54: 358-369.

21. Hsiao C, Van Riper M (2010) Research on care giving in Chinese families living with mental illness: A critical review. J FamNurs16: 68-100, February.

22. Abelenda J, Helfrich CA (2003) Family resilience and mental illness: the role of occupational therapist. OCC T Men Health19: 25-39.

23. Huang XY, Sun FK, YenWJ,CMF (2008)the coping experiences of carers who live with someone, who has schizophrenia. Journal of Clinical Nursing817-826.

24. Zergaw A, Hailemariam D, Alem A,Kebede A (2008) Longitudinal comparative analysis of economic and family caregiver burden due to Bipolar disorder. AJOP 11: 191-198.
25. Feitsma A (2005) Experiences and support needs of poverty stricken people living with HIV in Potchefstroom district in the North West Province. Potchefstroom North-West University 5-13.

26. Botes AC (2002) Botes model paradigm document. University of Johannesburg School of Nursing Paradigm. Johannesburg 1-13.

27. Burns N, Grove SK (2005) the practice of nursing research. Conduct, critique and utilization. 5thedn. Texas; Elsevier Saunders56-57.

28. Brink HL, Van der Walt C, Van Rensburg G (2006) Fundamental of research methodology for health care professionals. 3rdedn. Cape TownJuta: 113-114.

29. Henning E, Van Rensburg W, Smit B (2004) Finding your way in qualitative research. Pretoria Van Schaik.

30. Klopper H (2008) Qualitative research proposal. Curationis 31: 62-72.

31. Sales CA, Schuhli PAP, Dos Santos EM, Waidman MAP, Marcon SS (2010) Experiences of relatives in their care of schizophrenia persons: a phenomenological focus. Rev. Eletr. Enf12: 456-463.

32. Lee C, Kon N, Shu B (2006) Experiences of caring for family with mental illness from the perspective of male care givers [Chinese]. J Evid Based Nurs2: 180-188.

33. Trondsen MV (2012) Living with a mentally ill parent: Exploring adolescences" and perspectives. Qual Health Res22: 174-188.

34. Lauber C, Rossler W (2007) Stigma towards people with mental illness in developing countries in Asia. Int Rev of Psych19:157-178.

35. Jivanjee P, Kruzick J (2011) Support for young people with mental health conditions and their families in the transition years: Young and family voices. Bes PracMentHealth7:115-133. 